\title{
Photodynamic therapy for enhancing antitumour immunity
}

\author{
Klara Pizova, Katerina Tomankova, Adela Daskova, Svatopluk Binder, Robert Bajgar, Hana Kolarova
}

\begin{abstract}
Background. Photodynamic therapy (PDT) is a new modality in cancer treatment. It is based on the tumour-selective accumulation of a photosensitizer followed by irradiation with light of a specific wavelength. PDT is becoming widely accepted owing to its relative specificity and selectivity along with absence of the harmful side-effects of chemo and radiotherapy. There are three known distinct mechanisms of tumour destruction following PDT, generation of reactive oxygen species which can directly kill tumour cells, tumour vascular shutdown which can independently lead to tumour destruction via lack of oxygen and nutrients and thirdly enhanced antitumour immunity.

Methods. A review based on the literature acquired from the PubMed database from 1983 with a focus on the enhanced antitumour immunity effects of PTD.

Results and conclusion. Tumour cell death is accompanied by the release of a large number of inflammatory mediators. These induce a non-specific inflammatory response followed by gradual adaptive antitumour immunity. Further, a combination of PDT with the immunological approach has the potential to improve PDT efficiency and increase the cure rate. This short review covers specific methods for achieving these goals.
\end{abstract}

Key words: photodynamic therapy, photosensititizer, cancer, antitumour imunity, antibody

Received: November 2, 2011; Accepted with revision: May 17, 2012; Available online: June 14, 2012

http://dx.doi.org/10.5507/bp.2012.056

Department of Medical Biophysics, Faculty of Medicine and Dentistry and Institute of Molecular and Translational Medicine, Palacky University Olomouc, Czech Republic

Corresponding author: Hana Kolarova, e-mail: hana.kolarova@upol.cz

\section{INTRODUCTION}

Phototodynamic therapy (PDT) is promising new modality to combat cancer. It can be defined as the administration of a non-toxic drug or dye known as a photosensitizer (PS) either systemically, locally, or topically to a patient with a lesion/tumour. After an incubation period, the lesion/tumour is targtted with a visible light of specific wavelength determined by the PS used. In the presence of oxygen, this leads to the generation of reactive oxygen species (ROS), cell death and tumour tissue destruction (Fig.1). The use of PDT as a cancer therapy is particularly attractive owing to its specificity and selectivity as the PS concentrates specifically within the malignant tissue ${ }^{1-4}$. For this reason, PDT is becoming a major subject of intense investigation as a possible treatment modality for various forms of cancer. One considerable advantage is fact that PDT is minimally invasive, much cheaper and has less harmful side-effects than conventional chemotherapy, radiotherapy or surgery ${ }^{2,4,6}$.

Three mechanisms are known to contribute to the observed reduction and often disappearance of tumours treated with PDT. First, PDT induces generation of ROS which kill tumour cells directly by apoptosis and/or necrosis. Second, it induces destruction of tumour-associated vasculature, which can lead to tumour death via lack of oxygen and nutrients. Lastly, PDT triggers the recruitment of inflammatory and immune mediators causing an invasion of leukocytes that can both contribute to tumour destruction as well as stimulate the immune system to recognize and destroy tumour cells even at isolated locations
(Fig. 2) (ref., ${ }^{2,3}$ ). Direct induction of tumour cell death potentiated by ischemia is responsible for early tumour ablation. However, accumulating evidence indicates that these early events trigger inflammatory responses that are important in achieving long-term tumour control ${ }^{7}$.

In this short review, we focus on the ability of PDT to enhance antitumour immunity. Complicating the matter,

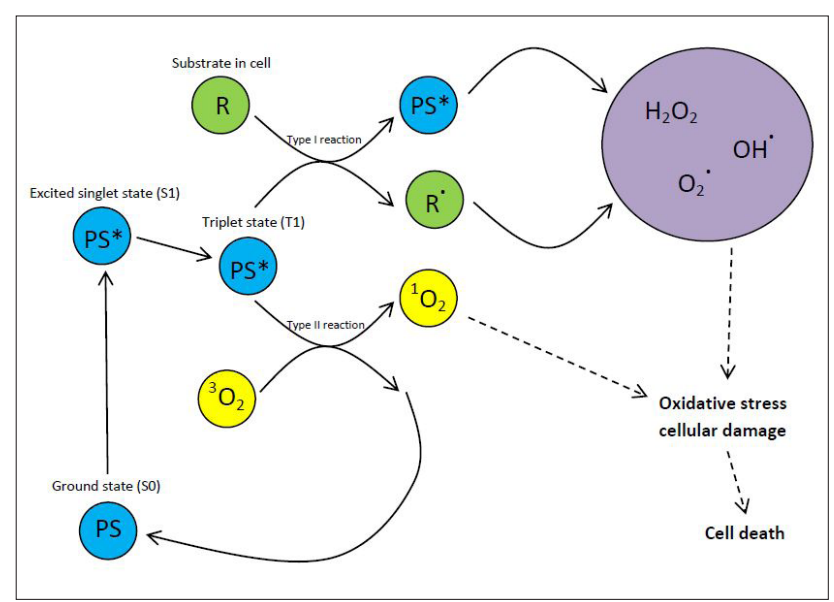

Fig. 1. A basic principle of PDT: When PS in cells is exposed to specific wavelengths of light, the PS in its singlet ground state ( $\mathrm{S} 0$ ) transforms to an excited singlet state (S1), which is followed by intersystem crossing to an excited triplet state (T1). Transfer energy from T1 to biological substrates and molecular oxygen, via type I and II reactions, generates $\operatorname{ROS}\left({ }^{1} \mathrm{O}_{2}, \mathrm{H}_{2} \mathrm{O}_{2}\right.$, $\mathrm{O} 2 \bullet, \mathrm{OH} \bullet$ ). This causes cellular damage which can lead to tumour cell death ${ }^{2,4,5}$. 
current evidence suggests that PDT may suppress some parts of the immune system while it stimulates others. The effects of PDT therefore appear to be more complex than a simple phototoxic reaction in cells accumulating a PS (ref. $\left.{ }^{8,9}\right)$.

\section{HOW PDT ENHANCES ANTI-TUMOUR IMMUNITY}

\section{Innate immunity against tumours}

\section{Initiation of inflammation}

It is known that PDT causes oxidative stress which triggers a vast array of signal pathways via toll-like receptors (TLRs) that induce protective responses. This includes expression of heat shock proteins (HSPs), transcription factors such as nuclear factor $\kappa \mathrm{B}(\mathrm{NF}-\mathrm{\kappa B})$ and activator protein 1 (AP-1) (ref. ${ }^{7}$ ). The increased activity of these transcription factors has been reported in a number of studies. Ryter and Gomer ${ }^{10}$ found that NF-kB binding activity in mouse leukemia cells was elevated 10fold after Photofrin-PDT. Legrand-Poels et al. ${ }^{11}$ observed NF- $\kappa$ B activation after proflavine-PDT. Matroule et al. ${ }^{12}$ perceived two waves of NF- $\mathrm{B}$ activation after PDT with pyropheophorbide-a methyl ester in human colon carcinoma cells. The first wave had maximal intensity between 10 and $30 \mathrm{~min}$ after irradiation. The intensity then decreased and almost disappeared after $1 \mathrm{~h}$. A second wave could then be observed $2 \mathrm{~h}$ after irradiation. In contrast to the first wave of activation, the second appeared slowly and was sustained for up to $24 \mathrm{~h}$. Similar results were described by Granville et al. ${ }^{13}$ on human HL-60 cells after PDT with benzoporphyrin derivative (BPD) - verteporfin. Kick et al. ${ }^{14}$ found that Photofrin-PDT induces AP-1 activation on HeLa (cervical carcinoma) cells. Gollnick et al. ${ }^{15}$ described similar results on epithelial PAM 212 cells. AP-1 activity was increased $3 \mathrm{~h}$ after Photofrin-PDT and remained elevated up to $6 \mathrm{~h}$ after treatment. Wild et al. ${ }^{16}$ studied RNA expression profiles of normal (UROtsa) and tumour cells (RT4 from bladder tumour and HT29 from colorectal adenocarcinoma) after ALA-PDT. They revealed increased expression of FOS gene in all three cell lines. Ruhdorfer et al. ${ }^{17}$ observed strongly increased expression of c-JUN and c-FOS in A-431 human squamous cell carcinoma cells after PDT with 5-aminolaevulinic acid (ALA). Sanovic et al. ${ }^{18}$ obtained similar results on A-431 cells and human fibroblasts after hypericin-PDT. FOS and JUN form the AP-1.

\section{Cytokine release}

NF- $\kappa$ B and AP-1 can then induce expression of immunoregulatory and proinflammatory proteins such as interleukins (IL-1 $\alpha,-1 \beta,-2,-6,-8,-11,-12,-15)$, tumour necrosis factor (TNF), chemokines (inflammatory protein IP-10, keratinocytes-derived chemokines $\mathrm{KC}$, macrophage inflammatory proteins MIP- $1 \alpha$ and $\beta$, MIP-2, eotaxin, Methyl-accepting Chemotaxis Protein MCP-1, RANTES) and interferons (IFN- $\alpha$ and $\beta$ ) (ref. $\left.{ }^{7}\right)$. For example Gollnick et al. ${ }^{15}$ in a study mentioned earlier, observed in addition to PDT-induced AP-1 activation also increased IL-10 expression and secretion. They also revealed that PDT prolongs the half-life of IL-10 mRNA. Gollnick et al. ${ }^{19}$ detected enhanced expression of MIP-2, KC and IL-6 in mice that received PDT with 2-[1-hexyloxyethyl]-2-devinyl pyropheophorbide-a (HPPH). HPPH-PDT induced a significant increase in IL-6 levels not only at tumour treated sites but also in the blood of treated mice. They also observed a trend towards increased levels of MIP-1 $\alpha$ in treated tumours 24 and $48 \mathrm{~h}$ post-treatment but the changes were not significant. Later Seshadri and Bellnier ${ }^{20}$ observed a significant increase in IL-6 levels after HPPH-PDT. They also tested the combination of PDT with adjuvant therapy (mentioned later) using 5,6-dimethylxanthenone-4-acetic acid (DMXAA). The combined therapy resulted in a marked increase in IL-6 over levels seen after PDT or DMXAA administration alone. Yom et al. ${ }^{21}$ detected increased levels of interleukins IL-1 $\beta$, IL-6, IL-8 and IL-10 in patients after surgery and Foscan-PDT. Korbelik et al. ${ }^{22}$ demonstrated that macrophages coincubated with squamous-cell carcinoma (SCCVII) cells treated with Photofrin-PDT become activated to produce TNF- $\alpha$. The results showed a significant increase in TNF- $\alpha$ levels in macrophages coincubated with PDT-treated SCCVII cells compared with macrophages incubated alone or with nontreated SCCVII cells. Kushibiki et al. ${ }^{23}$ also studied levels of cytokine secretion from mouse dendritic cells (DCs) coincubated with lysates of Lewis lung carcinoma cells treated by PDT with Talaporfin sodium (mono-L-aspartyl chlorin e6, Laserphyrin). The highest increase was observed for IL- $1 \alpha$, IL-1 $\beta$ and IL-6.

Neutrophil infiltration of tumour site and neutrophilia

Further, photooxidative degradation of membrane lipids and generation of arachidonic acid metabolites are themselves potent inflammatory mediators that cause a rapid and strong inflammatory reaction. These processes together with the release of histamine and serotonin from damaged vasculature cause infiltration of the tumour site by diverse populations of immune cells (neutrophils, mast cells and macrophages) that become activated and engaged in tumour cell destruction ${ }^{7,24-26}$. Neutrophils seems to play a role in the direct killing of tumour cells as well as in the activation of other immune cells. They are also a source of pro-inflammatory mediators ${ }^{26}$. A number of studies show that neutrophils not only accumulate in large numbers in PDT-treated tumours but they also appear in high levels in the blood of the host (so-called neutrophilia) $\left(\right.$ ref. ${ }^{27}$ ). For example, Cecic et al. ${ }^{28}$ reported that treatment of EMT6 tumors with a 50\% curative dose of PhotofrinPDT produced in the host mice an up to 2,6-fold rise in the percentage of blood neutrophils which persisted for at least $10 \mathrm{~h}$ after treatment. Cecic and Korbelik ${ }^{27}$ also observed marked enhancement of blood neutrophils after Photofrin-PDT. Gollnick et al. ${ }^{19}$ demonstrated that HPPH-PDT, in a dose that achieved long-term tumour suppression in $\sim 50 \%$ of animals, resulted in a modest 
(no more than three-fold over controls), time-dependent increase in percentage of neutrophils in the treated tumour. The neutrophil level remained elevated for at least $72 \mathrm{~h}$ post-treatment. Cecic et al. ${ }^{29}$ observed two peak neutrophilia levels in mouse blood after Photofrin-PDT. The early phase decreasing $3 \mathrm{~h}$ after treatment and the advanced phase with a maximum approximately $8 \mathrm{~h}$ after treatment. After the second peak, the intensity of neutrophilia steadily decreased, approaching pretreatment levels $24 \mathrm{~h}$ after PDT.

As mentioned, neutrophilia elicited in mice bearing PDT-treated tumors results from the integrated action of multiple mediators that are massively released from the targeted lesion. However, a key event appears to be PDTinduced complement activation ${ }^{27,29}$.

\section{Complement activation}

The complement system is a biochemical cascade integrating over 30 serum and cell surface proteins ${ }^{30}$. It is the major effector system of innate immunity and seems to play an important role in the PDT-induced response ${ }^{7,26}$. Complement engagement can be triggered by one of three independent activation pathways - classical, alternative or lectin mediated ${ }^{30,31}$. Complement cascade after PDT is likely activated by the alternative pathway ${ }^{26,28,32,33}$. The complement system is engaged at multiple levels in tu- mour PDT response including the initial recognition of tumour damage, initiation and boosting of inflammatory response and removal of dead tumour cells ${ }^{34}$.

As mentioned above, PDT results in activation of the complement system. For example Cecic et al. ${ }^{33}$ assessed C3 content in Photofrin-PDT-treated tumours and revealed a marked increase in levels of this protein, peaking $3 \mathrm{~h}$ after therapy and remaining highly elevated up to 24 $\mathrm{h}$ post PDT. Similar findings were reported by Cecic et al. ${ }^{36}$. These authors found that complement activity was elevated immediately after Photofrin-PDT, increased about two-fold at the peak interval of $6 \mathrm{~h}$ post PDT, remained elevated during the next $6 \mathrm{~h}$, and declined to pre-treatment levels $24 \mathrm{~h}$ post PDT. Cecic et al. ${ }^{37}$ found significantly elevated C3 content in tumour tissue $3 \mathrm{~h}$ after PDT with Photofrin or BPD but the extent of the increase was much higher with Photofrin-PDT than with BPD-PDT. Korbelik $^{34}$ observed that C3 levels in macrophages infiltrating PDT-treated sites increased $30 \mathrm{~min}$ after therapy with Photofrin and remained elevated 18 hours later. Cecic and Korbelik ${ }^{38}$ showed that Photofrin-PDT induces the fixation of complement $\mathrm{C} 3$ protein (probably in the form of its activated fragments) and of the terminal complement membrane attack complex on the treated SCCVII cells. Stott and Korbelik ${ }^{39}$ assessed expression of $\mathrm{C} 3, \mathrm{C} 5$ and $\mathrm{C} 9$ genes in tumours and they showed that

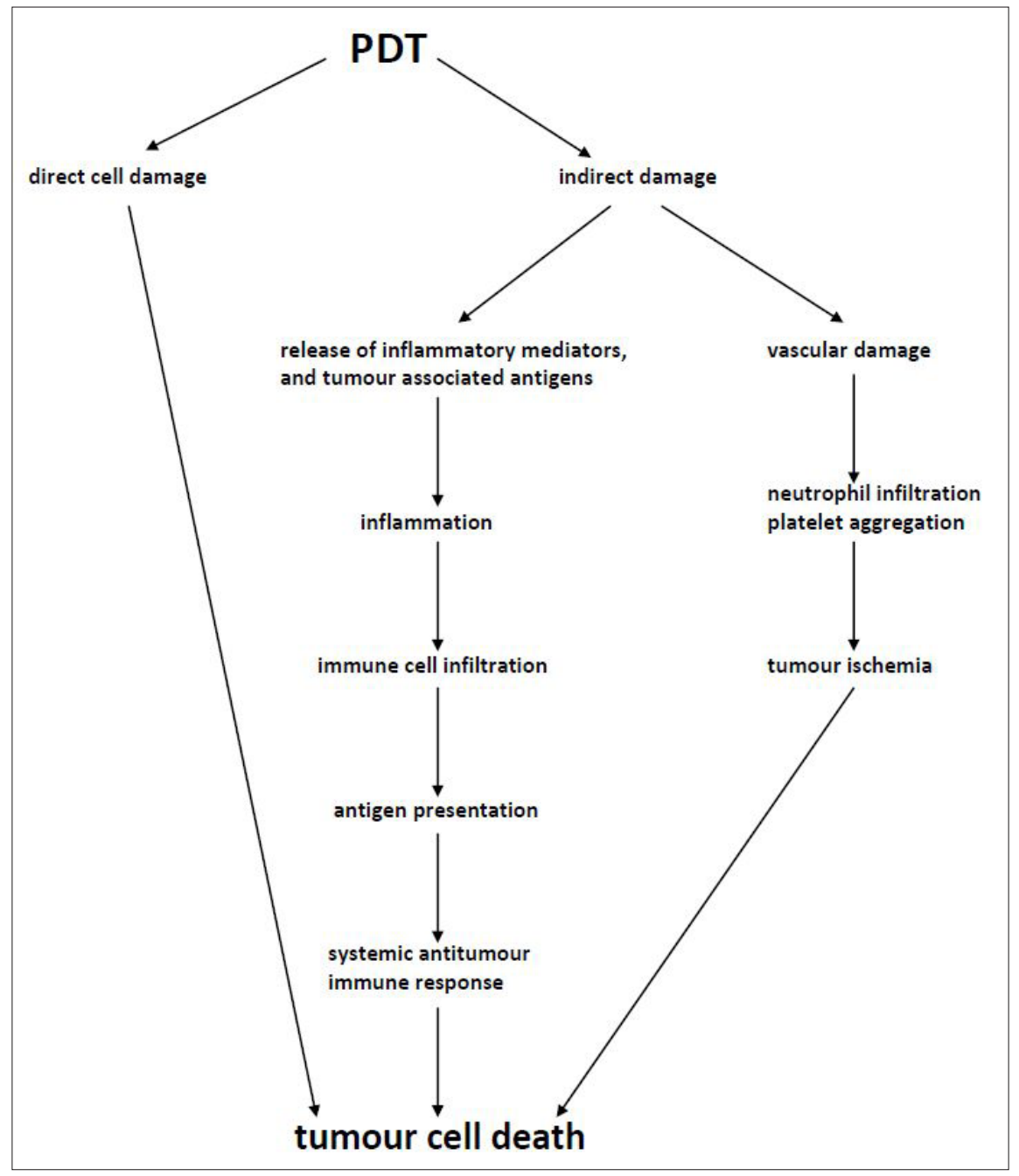

Fig. 2. The mechanisms of antitumour effects triggered by PDT. In the first case, PDT induces generation of reactive oxygen species (ROS) which directly can kill tumour cells by apoptosis and/or necrosis. Moreover, tumour cells apoptosis and necrosis accompanied by the release of numerus inflammatory mediators (such as cytokines) and tumor-associated antigens. These mediators induce a non-specific inflammatory response followed by a slowly developing adaptive immunity. Lastly, PDT induces destruction of tumour-associated vasculature, which can lead to tumour death via lack of oxygen and nutrients ${ }^{7,35}$. 
all three complement genes were signifcantly up-regulated $24 \mathrm{~h}$ after Photofrin-PDT. This increase was over threefold with $\mathrm{C} 3$ and $\mathrm{C} 5$ genes and somewhat lower with the C9 gene. Results from Korbelik and $\mathrm{Cecic}^{40}$ revealed that macrophages infiltrating PDT-treated sites tend to have not only up-regulated complement gene expression such as C3, C5 and C9 but conversely have down-regulated certain membrane-bound complement regulatory proteins such as decay accelerating factor - DAF, protectin and mouse-specific complement-receptor-1-related protein y - Crry. These regulatory proteins resist complement deposition in cell membranes and protect host cells from inadvertent complement attack.

A complement system is not only an effector of innate imunity. It can also play a role in adaptive immunity. Particularly, it has been found that complement system directly promotes T-cell mediated response $\mathrm{e}^{30,31,41,42}$.

\section{Adaptive immune response against tumour}

A photosensitization induces the innate immunity response with subsequent development of adaptive immunity. An acute inflammatory reaction develops during the first hours/days following the treatment but as tumour cells undergoing necrotic or apoptotic death release their antigens into the surrounding inflammatory milieu. Released antigens are taken up by antigen presenting cells (APC) and antigen presentation strongly promotes formation of specific antitumour immunity ${ }^{43}$.

Kabingu et al. ${ }^{44}$ demonstrated that Photofrin-PDT of murine EMT6 tumours provided durable growth inhibition of untreated tumours. The growth inhibition of tumours outside the treatment field was tumour-specific and dependent on the presence of CD8+ T cells. Preise et al..$^{43}$ found that adoptively transferred CD8+ and CD4+ T-cells from surviving mice 3 months postVTP (vascular targeted photodynamic therapy) with the photosensitizer WST11 (bacteriocholorophyll derivative) were able to protect naïve recipients from subsequent challenge with viable cancer cells. A marked B-cell infiltration was also observed $24 \mathrm{~h}$ after treatment in the tumour rim, 1 week after VTP Preise et al. ${ }^{43}$ detected increased serum IgG titers compared with serum from naïve and untreated tumour-bearing mice. Moreover, they found that in contrast to PDT with hematoporphyrin-based and other PSs that always induced tumour-specific immunity, protection induced by WST11-VTP was found to be nontumour-specific. Mice cured of local mouse 4T1 mammary tumours resisted the challenge with CT26 cells.

There is similar evidence from human studies. Thong et al. ${ }^{45}$ demonstrated in multifocal angiosarcoma of the head and neck carcinoma, increased CD8+ T cell infiltration into the treated tumour after PDT with Fotolon (comprises chlorin e6 and polyvinylpyrrolidone in the ratio $1: 1)$. Kabingu et al. ${ }^{46}$ showed enhanced recognition of major histocompatibility complex (MHC) class I - antigen complexes by immune cells after PDT with Photofrin or ALA in patients with basal cell carcinoma. This study also suggests that PDT enhances activation of tumour specific CD8+ T cells which require MHC-I - antigen recognition for activation.

\section{IMMUNOSUPPRESSIVE EFFECT OF PDT}

As mentioned above, certain PDT regimens have been shown to systemically suppress immune reactivity ${ }^{46}$.

Elmets and Bowen ${ }^{47}$ were the first to find that PDT with hematoporphyrin derivative results in immunosuppression. Musser and Oseroff ${ }^{48}$ studied the immune response after Photofrin-PDT and found that even a small area of exposure results in immunosuppression. Gollnick et al. ${ }^{49}$ also discovered that cutaneous Photofrin-PDT causes suppression of the contact hypersensitivity (CHS) reaction. They revealed PDT dependent increase in levels of IL-10 expression in the sera of treated animals. It is known that IL-10 suppresses cell-mediated immune responses via its ability to inhibit activation of Th1 cells by APC but this study also demonstrated that IL-10 does not play a role in CHS suppression by cutaneous PDT. The major effector cell in CHS is the IFN- $\gamma$ secreting CD8+ (Tc1) cell. Therefore, it is possible that PDT induces a defect in the development of Th1 and Tc1 cells. Another potential suppressor of Th1 and Tc1 development, and thus CHS, is IL-4. Induction of IL-4 by PDT may cause direct inhibition of the Th1 or Tc1 cell. Data from their group suggests that cutaneous PDT results in the induction of systemic IL-4. Hayami et al. ${ }^{50}$ obtained similar results. They found that ALA-PDT resulted in a decreased number of epidermal Langerhans cells and their morphological changes. Their data also indicate that supression of CHS induced by PDT is systemic (CHS response to an antigen applied to PDT-untreated skin was suppressed when a greater dose of visible light was used on ALA-treated skin) and antigen specific. Yusuf et al. ${ }^{51}$ observed that immunosuppression caused by PDT with silicon phthalocyanine Pc4 can be adoptively transferred. Their results also suggest that CD4+ T cells are at least in part responsible for Pc4-PDT-induced immunosuppression and CD8+ T cells also contribute to this immunosuppressive effect. Matthews and Damian ${ }^{52}$ studied the immune response after PDT with ALA and methyl aminolaevulinate (MAL) on human and found that both MAL-PDT and ALA-PDT cause significant immunosuppression. However, they observed immunosuppressive effects only in the treated area of skin. It was not a systemic effect.

The switch from immune enhancing to immune suppressing effects of PDT appears to be linked to the area of skin treated. Whole body light irradiation in combination with PS resulted in immune suppression in several model systems ${ }^{53}$. Kabingu et al. ${ }^{46}$ showed that treatment of large surface areas leads to immune suppression rather than immune stimulation, which may indicate that enhancement of anti-tumour immunity is inversely related to the area treated. 


\section{THERAPEUTIC IMPLICATIONS (METHODS FOR IMPROVING THE THERAPEUTIC OUTCOME OF PDT)}

The extensive involvement of PDT in inducing immune response leads to an attempt to optimize PDT efficacy through the modulation of important inflammatory and immune mediators. The activation of a specific and systemic host immune response may result in not only destruction of remaining local tumour cells but also the prevention of possible recurrence and metastasis. Moreover, the antitumour efficacy of PDT could be enhanced through an effective immunoadjuvant to further expand its usefulness for a possible control of distant metastasis and recurrence. However, in clinical practice, the optimal PDT regimen for achieving tumour ablation might be different from the optimal PDT regimen for producing immune response ${ }^{54}$. Immunological approaches used to potentiate PDT in general can be divided into non-specific and specific methods ${ }^{55}$.

\section{Non-specific methods}

Non-specific methods are based on the administration of substances which can influence, regulate and potentiate the activity of the immune system, and, therefore, indirectly affect cancer progression ${ }^{55}$.

For example, Gołąb et al. ${ }^{56}$ used a combination of Photofrin-PDT and granulocyte colony-stimulating factor (G-CSF), endogenous cytokine that regulates granulocyte biofunctions and plays major roles in the stimulation of granulopoesis. They revealed that intensive treatment with G-CSF significantly potentiates the anti-tumour efficacy of Photofrin-PDT (manifested as a reduction of tumour growth and a prolongation of mice survival time). Also neutrophil infiltrations were substantially greater in tumours treated with the combined therapy. Bellnier ${ }^{57}$ found that other cytokine, recombinant human TNF- $\alpha$, in combination with Photofrin-PDT provide additive antitumour efficacy against an implanted mouse tumour. However, TNF- $\alpha$ shows significant systemic toxicity at effective doses. In order to limit TNF- $\alpha$ toxicity, the same group started using agents that stimulate the synthesis of this cytokine preferentially in tumours. Bellnier et al.$^{58}$ studied the effect of the TNF- $\alpha$ inducing drug 5,6-dimethylxanthenone-4-acetic acid (DMXAA). The combined treatment with low-dose $(20 \mathrm{mg} / \mathrm{kg})$ DMXAA and low-dose $(1,5$ $\mathrm{mg} / \mathrm{kg}$ Photofrin plus $135 \mathrm{~J} / \mathrm{cm}$ light dose) PDT led to a reduction in tumour volume with a long delay in regrowth and resulted in an $18 \%$ cure rate at 90 days. This represents an enormous increase in efficacy of PDT in this tumour model. In addition, there was no systemic toxicity after combined therapy and no increased normal tissue toxicity compared with PDT alone. Also Seshadri et al. ${ }^{59}$ tested DMXAA in combination with PDT, but they used as PS, HPPH. Combined therapy at doses 25 $\mathrm{mg} / \mathrm{kg}$ DMXAA and the HPPH-PDT regimen $48 \mathrm{~J} / \mathrm{cm}^{2}$ resulted in $>70 \%$ long-term cure rate. Whereas DMXAA single therapy at the same dose resulted in only $5 \%$ cure rate at 90 days and HPPD-PDT single therapy in $0 \%$ cure rate at 90 days. Moreover combination therapy using PDT-DMXAA, in addition to showing enhanced antitumour activity also improved the selectivity of the response compared with PDT alone. A few years later, the same research group (Seshadri and Bellnier ${ }^{20}$ ) confirmed the same positive results.

Korbelik et al. ${ }^{32}$ studied possible complement activators (zymosan, streptokinase and urokinase). Tumour-localized treatment with zymosan reduced the recurrence-rate of PDT-treated tumours and markedly increased the percentage of permanent cures. Also systemic treatment with streptokinase, or a similar agent, urokinase, enhanced the PDT-mediated tumour response. Unfortunately it was revealed that zymosan exhibits severe side effect so it is not safe for clinical use, while streptokinase and urokinase are clinically acceptable but primarilly act as anticoagulating agents. Thus, their use is also not without risk ${ }^{55,60}$.

$\gamma$-inulin and IFN- $\gamma$ were found to be more promising adjuvant agent in PDT. $\gamma$-inulin is a potent activator of the alternative complement pathway. IFN- $\gamma$ is a cytokine that stimulates the phagocytic activity of macrophages and dendritic cells, and augments their antigen processing and presentation ability ${ }^{55,60}$. In the study of Korbelik and Cooper $^{60}$ the mice receiving $\gamma$-inulin immediately after photodynamic light treatment showed decreased tumour recurrence and higher cure rates compared to the PDT only group. Similar results were obtained with different photosensitisers (Photofrin, benzoporphyrin derivative monoacid $\mathrm{A}$, m-tetrahydroxyphenylchlorin and chlorin e6) on three different tumour models (melanoma B16BL6, fibrosarcoma MCA205 and fibrosarcoma FsaR).

Akramiene et al. ${ }^{61}$ tested $\beta$-glucans as adjuvant agent and the results showed that treatment with combination of Photofrin-PDT and $\beta$-glucans produces significantly larger necrotic area in tumour tissue than PDT alone. $\beta$-glucans are natural polysacharides that bind $\mathrm{C} 3$ receptor on the effector cells, thereby activate them to kill tumour cells. Without $\beta$-glucan, C3-opsonized tumour cells are resistant to killing because they lack $\beta$-glucan in their membrane. They found that this combined treatment positively modulates the photodynamic effect by inhibition of the DNA damage repair system and causing a cell proliferation decrease or by suppression of tumour angiogenesis. They observed that tumour tissue treated with $\beta$-glucan alone or in combination with PDT was less infiltrated by erythrocytes compared with nontreated tissue or tissue treated with PDT alone.

Separovic et al. ${ }^{62}$ tested the long-term curative potential of Foscan-PDT in combination with LCL29 (watersoluble cationic pyridinium ceramide analog) which accumulates preferentially in negatively-charged mitochondria of various cancer cell lines and has been implicated in tumour-suppressor function. PDT alone resulted in a $37.5 \%$ cure rate, LCL29 given immediately after PDT resulted in $75 \%$ cure rate and LCL29 given one day before PDT even $83.3 \%$. 
Coupienne et al. ${ }^{63}$ used an interesting approach on glioblastoma cells with ALA-PDT. As known PDT can induce NF- $\mathrm{kB}$ activation. However, Coupienne and his colleagues $^{63}$ found that NF-kB also plays a protective role against PDT-induced cell death and more particularly against necrosis. Hence, inhibition of NF-kB renders cells more sensitive to the PDT-treatment. Their results confirmed this idea. Glioblastoma cell survival was sharply decreased after ALA-PDT when NF-kB was inhibited either by treatment with BAY or by the presence of the undegradable form of $\mathrm{IkB} \alpha$ (nuclear factor of kappa light polypeptide gene enhancer in B-cells inhibitor, alpha).

As all these results show, such combined therapy allows a reduction in dose of PS or light without any reduction in treatment efficiency ${ }^{55}$.

\section{Specific methods}

Specific methods are based on the fact that cancer cells contain cancer-associated antigens. This can be utilized for photoimmunotherapy (PIT) or PDT combined with specific immunotherapy ${ }^{55}$.

\section{Photoimmunotherapy}

PIT uses PSs conjugated with monoclonal antibody or their fragments specific for an antigenic determinant on tumour cells. This enhances the tumour targeting of the PS. There are a number of studies using various PSs conjugated with various antibodies ${ }^{55}$.

The pioneering work on this field was a study by Mew et al. ${ }^{64}$ in which they used hematoporphyrin chemically coupled to monoclonal antibodies $(\mathrm{mAb})$ directed to the DBA/2J myosarcoma M-1. Administration of antiM-1-hematoporphyrin conjugates to M-1 tumour-bearing animals followed by exposure to activating light resulted in suppression of M-1 growth. Thus, in vitro experiments revealed that PIT may be a potent tool in cancer treatment but a number of issues remain to be resolved, especially, reduced phototoxicity of the PS immunoconjugate, limited penetration into solid poorly vascularized tumours and technical problems associated with chemical coupling. Most PSs used in photodynamic therapy are hydrophobic and lipophilic and tend to aggregate in aqueous solutions. For this reason, it not has been possible to conjugate them to water-soluble molecules such as antibodies. Hence, many PS immunoconjugates contained substantial amounts of free PS impurities and the target-specific effects of the PS immunoconjugates could not be clearly distinguished from nonspecific effects of free PS impurities ${ }^{65-67}$.

For example Savellano and Hasan ${ }^{68}$ used two methods to generate useful and efficient conjugates of BPD Verteporfin and antibody C225 (chimeric antibody to extracellular domain of the epidermal growth factor receptor EGFR). The first is polyethylenglycolation (PEGation) of antibody which dramatically enhances the solubility of PS immunoconjugate, and reduces their aggregation. Second is a $50 \%$ dimethyl sulfoxide - $50 \%$ aqueous two-solvent system which prevents PS aggregation and noncovalent interactions. Indeed PS immunoconjugate killed EGFR-overexpressing A-431 cells photodynamically but the results showed that it is not as effective as BPD alone. Savellano et al. ${ }^{69}$ used PEGation for generating conjugate of pyropheophorbide-a (PPa) with two different anti-HER2 mAbs, HER50 and HER66. This photosensitizer immunoconjugates specifically target and photodynamically kill HER2-overexpressing cells. The results also showed that multiepitope targeting is significantly more effective for photoimmunotherapy than single-epitope. However both HER50 and HER66 photosensitizer immunoconjugates still had lower binding affinities than their respective parent $\mathrm{mAbs}$ and were less phototoxic than free PPa.

Antibody fragments such as scFvs (single-chain Fv fragments) have been shown to be superior to whole antibodies in many aspects of tumour targeting such as speed of penetration and tumour:normal tissue specificity. Bhatti et al. ${ }^{70}$ used a conjugate of $\mathrm{PPa}$ with various scFvs (C6.5, MFE, HuBC-1). Coupling of all scFvs to the activated PSs was performed in an aqueous buffer containing DMSO and acetonitrile. This retained the solubility of the scFv, and allowed the hydrophobic PSs to remain in solution long enough for the reaction to proceed. This had been realized without the need for additional chemical manipulations of the antibody (e.g. PEGation). In vitro cell killing using C6.5-PPa showed a greater than 70-fold enhancement of $\mathrm{IC}_{50}$ (concentration of a drug that is required for $50 \%$ inhibition in vitro) over free $\mathrm{PPa}$ and MFE-PPa gave a 7-fold enhancement over free PPa. Moreover, the results show that the clearance of scFv-PPa conjugate is more rapid than free $\mathrm{PPa}$ or whole antibody. This suggests that the time between the administration of the scFv-PPa and light exposure could be shorter and thus therapeutically more attractive, resulted in very little danger of skin photosensitivity. Bhatti and coworkers ${ }^{70}$ also found that the number and distribution of lysine residues on the surface of the $\mathrm{scFv}$ may have a direct influence on the photophysical function of the PS coupled to them and determines the suitability of the scFv as a PS carrier. This can be exploited for the design of better photoimmunoconjugates.

\section{PDT combined with specific immunotherapy}

PDT combined with specific immunotherapy is easier to perform than PIT. For example Jalili et al. ${ }^{71}$ used adoptive transfer of immature DCs in combination with Photofrin-PDT on mice colon carcinoma. DCs are professional antigen-presenting cells and the most effective inducers of adaptive immunity. This research group built on the observations that PDT induces both necrotic and apoptotic death of tumour cells accompanied by oxidative stress and induction of HSPs. Therefore, PDT creates a unique environment suiable for releasing of tumour antigens and "danger" signals that could trigger maturation of DCs. The results show that a combination therapy approach using PDT and DCs is more effective than either procedure alone. This study also revealed that the effect 
of this combined treatment is not limited to the treated tumour but is also effective in the control of distant growth. Similar results was published by Saji et al. ${ }^{72}$ with a combination of intratumourally injected DCs and ATX-S10 $\mathrm{Na}$ (II)-mediated PDT. They also observed a dramatic effect on both local and distant tumours.

Instead of DCs, some tumour specific antibodies can be used. For example del Carmen et al. ${ }^{73}$ tested a combination regimen consisting of C225 (Erbitux, cetuximab), a monoclonal antibody that inhibits of EGFR (overexpression of which is associated with the development of resistant ovarian cancer), and BPD-PDT in a mouse model of human ovarian cancer. Under normal conditions, EGFR expression is critical for maintaining cellular homeostasis via receptor tyrosine kinase signaling pathways, such mitogen-activated protein kinase (MAPK) or phosphatidylinositol 3-kinase (PI3K) cascade. Increased MAPK and PI3K signaling results in unregulated cell proliferation. C225 blockade of EGFR activity prevents cancer cells which overexpress EGFR from aberrantly entering $\mathrm{S}$ phase, thereby inhibits unregulated progression through the cell cycle. Cancer cells that are highly dependent on these proliferative pathways become more vulnerable to additional therapeutic insult and are more effectively killed via a secondary modality, such as PDT. The combination therapy was well tolerated (required fewer treatments to achieve improved efficacy compared with monotherapy with minimal toxicity, less weight loss, and no treatment-related morbidity) and demonstrated improved survival.

Another approach was used by Jiang et al. ${ }^{74}$. Although PDT alone may shrink or destroy tumours, it can induce, as a side effect, angiogenesis (growth of new blood vessels). Among the most substantial mediators of angiogenesis are vascular endothelial growth factor (VEGF). VEGF is abundantly expressed in a variety of human tumours and its expression is strongly upregulated by hypoxia and oncogenes that are tightly associated with rapidly growing tumours. Thus, antiangiogenic treatment may provide additive anti-cancer efficacy in that the angiogenesis induced by PDT is abolished by the antiangiogenic agents. They inhibit the growth of tumour blood wessel thereby cutting off the tumour's nutritional supply and inhibit growth of tumour cells. Jiang and colleagues ${ }^{74}$ combined Photofrin-PDT with mAbs (MF1 and DC101) against vascular endothelial growth factor receptors on intracranial glioblastoma in mice. The results showed that combination therapy inhibits glioblastoma angiogenesis, leading to a decrease in tumour volume and an extension in survival time, with better anti-cancer efficacy than PDT or antiangiogenic agents administered alone. Bhuvaneswari et al. ${ }^{75}$ obtained similar positive results when they used $\mathrm{mAb}$ against VEGF (Avastin, bevacizumab) in combination with hypericin-PDT on mice bladder carcinoma tumours.

Another possible method was published by Korbelik and $\mathrm{Cecic}^{40}$. As mentioned earlier, they found that in vivo Photofrin-PDT diminished expression of DAF, protectin and mouse-specific Crry present on murine SCCVII cell surface thereby making these cells susceptible to comple- ment component deposition and efficient removal by phagocytes. In order to amplify this effect, following PDT, mice were injected with antibodies against either Crry, protectin, or DAF. PDT with anti-Crry and anti-protectin resulted in increased tumour cure rate compared to PDT alone, while the reverse was found with PDT plus antiDAF combination, likely owing to the additional role of DAF in $\mathrm{T}$ cell signaling.

\section{PDT-generated vaccine for cancer therapy}

The ability of PDT to induce an antitumour immune response associated with efficient recognition of tumour antigens has prompted the speculation that PDT can be exploited for the generation of an anticancer vaccine ${ }^{76}$. Indeed, a number of studies confirmed this theory.

In contrast to PDT, in vaccine application, the PS is not administered to the host nor is the tumour exposed to light. Instead, the host is injected with a vaccine consisting of autologous tumour cells or their lysates treated by PDT in vitro ${ }^{77}$. Korbelik and Sun ${ }^{76}$ produced whole cancer cell therapeutic vaccine by incubating in vitro expanded mouse SCCVII cells with BPD, then exposing them to light. Treatment of established subcutaneous SCCVII tumours with this vaccine by a peritumoural injection produced a significant therapeutic effect, including growth retardation, regression and cure. The results also showed that there was a marked increase in cell numbers within all major lymph node populations in vaccinated mice compared to nonvaccinated tumour-bearing mice. The same team (Korbelik et al ${ }^{78}$ ) tested cancer vaccines prepared by treating mouse SCCVII cells with chlorin e6-based PDT. Their study demonstrated that the effectiveness of the PDT vaccine was increased when vaccine cells remained in culture after PDT treatment for an additional time interval to allow the expression of PDT-induced molecular/ biological changes in these cells. Such changes of possible relevance include the progression of apoptotic or necrotic death process associated with the appearance of death signal molecules on the cell surface. Korbelik and coworkers $^{78}$ also revealed that although the PDT vaccine induced antitumour immune response is of a systemic nature (and cured mice resist tumour re-challenge), the proximity of vaccination site to the treated lesion is relevant for the therapy outcome. PDT vaccines injected at a distal site were still effective, but their impact was inferior to perilesional treatment. Zhang et al. ${ }^{79}$ adopted the PDT method with hematoporphyrin monomethyl ether (HMME) as the PS to prepare the vaccine against H22 (mouse hepatoma cells) tumour. They found that the PDT-generated vaccine increased the percentages of CD4+, CD8+ and CD19+ cells, inhibited tumour growth, and prolonged the survival time. Shixiang et al. ${ }^{80}$ generated vaccines by exposing DCs to C6 glioma cancer cell antigenic (tumour) peptides following exposure of $\mathrm{C} 6$ cells to HMME-PDT and acid elution. They revealed that PDT-generated antigens further purified by acid elution had the greatest stimulatory effect on DCs based on the elevated serum 
IL-12 and TNF- $\alpha$ levels and decreased serum IL-10 levels. This vaccine based on PDT-acid elution seems to be more effective than previous whole-cell PDT vaccines.

These studies demonstrate that PDT can be exploited for the generation of effective therapeutic cancer vaccines. Tumour growth can be inhibited with a vaccine generated from in vitro PDT-treated tumor cells of the same origin ${ }^{76}$

\section{CONCLUSION}

Blood vessel occlusion, ischemia and direct destruction of the tumour cells caused by PDT lead to local inflammation and infiltration of the tumour by immune cells such as neutrophils, macrophages and mast cells. As mentioned, PDT can trigger not only innate immunity but also the adaptive one. Tumour antigens released from demaged cells during PDT are phagocytosed, processed by macrophages and presented in the context of MHC class II. This contributes to the development of the systemic antitumour immune response. Adaptive antitumour immunity may result in remission of untreated metastases and other tumours localized distally to the primary treated tumour. A combination of PDT with the immunological approach opens possibilities for considerable improvement of the PDT efficiency and increases the cure rate ${ }^{55}$. However, not all details are known and many more preclinical and clinical experiments need be done.

\section{ABBREVIATIONS}

ALA, 5-aminolaevulinic acid; AP-1, activator protein 1; APC, antigen presenting cell; BAY, 3-[(4-methylphenyl)sulfonyl]-(2E)-propenenitrile; BPD, benzoporphyrin derivative; CHS, contact hypersenzitivity; Crry, complement-receptor-1-related protein y; DAF, decay accelerating factor; DCs, dendritic cells; DMXAA, 5,6-dimethylxanthenone-4-acetic acid; EGFR, epidermal growth factor receptor; G-CSF, granulocyte colony-stimulating factor; HMME, hematoporphyrin monomethyl ether; HPPH, 2-[1-hexyloxyethyl]-2-devinyl pyropheophorbide-a; HSPs, heat shock proteins; IFN, interferon; IgG, imunoglobulin G; IL, interleukin; IP, inflammatory protein; IkB $\alpha$, nuclear factor of kappa light polypeptide gene enhancer in B-cells inhibitor, alpha; $\mathrm{KC}$, keratinocytes-derived chemokine; mAb, monoclonal antibody; MAL, methyl aminolaevulinate; MAPK, mitogen-activated protein kinase; MCP, Methyl-accepting Chemotaxis Protein; MHC, major histocompatibility complex; MIP, macrophage inflammatory protein; NF- $\mathrm{B}$, nuclear factor $\kappa \mathrm{B}$; Pc4, phthalocyanine 4; PDT, phototodynamic therapy; PEGation, polyethylenglycolation; PIT, photoimmunotherapy; PI3K, phosphatidylinositol 3-kinase; PPa, pyropheophorbide-a; PS, photosensitizer; RANTES, Regulated upon Activation, Normal T-cell Expressed, and Secreted [chemokine (C-C motif) ligand 5 - CCL5]; ROS, reactive oxygen species; SCCVII, squamous-cell carcinoma; scFv, single-chain Fv fragment; Tc, cytotoxic T cell; Th, T helper cell; TLR, toll-like receptor; TNF, tumour necrosos factor; VEGF, vascular endothelial growth factor; VTP, vascular targeted photodynamic therapy.

\section{ACKNOWLEDGEMENTS}

Supported by the grants No. CZ.1.05/2.1.00/01.0030 and LF_2011_009.

\section{REFERENCES}

1. Kolarova H, Tomankova K, Bajgar R, Kolar P, Kubinek R. Photodynamic and sonodynamic treatment by phthalocyanine on cancer cell lines. Ultrasound Med Biol 2009;35:1397-404.

2. Robertson $\mathrm{CA}$, Evans $\mathrm{DH}$, Abrahamse H. Photodynamic therapy (PDT): a short review on cellular mechanisms and cancer research applications for PDT. J Photochem Photobiol B 2009;96:1-8.

3. Olivo M, Bhuvaneswari R, Lucky SS, Dendukuri N and Soo-Ping Thong P. Targeted Therapy of Cancer Using Photodynamic Therapy in Combination with Multi-faceted Anti-Tumor Modalities. Pharmaceuticals 2010;3:1507-29.

4. Agostinis $P$, Berg K, Cengel KA, Foster TH, Girotti AW, Gollnick SO, Hahn SM, Hamblin MR, Juzeniene A, Kessel D, Korbelik M, Moan J, Mroz P, Nowis D, Piette J, Wilson BC, Golab J. Photodynamic therapy of cancer: an update. CA Cancer J Clin 2011;61:250-81.

5. Juarranz A, Jaén P, Sanz-Rodríguez F, Cuevas J, González S. Photodynamic therapy of cancer. Basic principles and applications. Clin Transl Oncol 2008;10:148-54.

6. O'Connor AE, Gallagher WM, Byrne AT. Porphyrin and nonporphyrin photosensitizers in oncology: preclinical and clinical advances in photodynamic therapy. Photochem Photobiol 2009;85:1053-74.

7. Nowis D, Stokłosa T, Legat M, Issat T, Jakóbisiak M, Gołąb J. The influence of photodynamic therapy on the immune response. Photodiagnosis and Photodynamic Therapy 2005;2:283-98.

8. Gollnick SO, Brackett CM. Enhancement of anti-tumor immunity by photodynamic therapy. Immunol Res 2010;46:216-226.

9. Jemec GBE. Photodynamic therapy. In: Jemec GBE, Kemeny L, Miech $D$, editors. Non-Surgical Treatment of Keratinocyte Skin Cancer. Heidelberg, Dordrecht, London, New York: Springer; 2010. p.133-5.

10. Ryter SW, Gomer CJ. Nuclear factor kappa B binding activity in mouse L1210 cells following photofrin II-mediated photosensitization. Photochem Photobiol 1993;58:753-6.

11. Legrand-Poels S, Bours V, Piret B, Pflaum M, Epe B, Rentier B, Piette J. Transcription factor NF-kappa $B$ is activated by photosensitization generating oxidative DNA damages. J Biol Chem 1995;270:6925-34.

12. Matroule JY, Bonizzi G, Morlière P, Paillous N, Santus R, Bours V, Piette J. Pyropheophorbide-a methyl ester-mediated photosensitization activates transcription factor NF-kappaB through the interleukin-1 receptor-dependent signaling pathway. J Biol Chem 1999;274:29883000.

13. Granville DJ, Carthy CM, Jiang H, Levy JG, McManus BM, Matroule JY, Piette J, Hunt DW. Nuclear factor-kappaB activation by the photochemotherapeutic agent verteporfin. Blood 2000;95:256-62.

14. Kick G, Messer G, Goetz A, Plewig G, Kind P. Photodynamic therapy induces expression of interleukin 6 by activation of AP-1 but not NF-kappa B DNA binding. Cancer Res 1995;55:2373-9.

15. Gollnick SO, Lee BY, Vaughan L, Owczarczak B, Henderson BW. Activation of the IL-10 gene promoter following photodynamic therapy of murine keratinocytes. Photochem Photobiol 2001a;73:170-7.

16. Wild PJ, Krieg RC, Seidl J, Stoehr R, Reher K, Hofmann C, Louhelainen J, Rosenthal A, Hartmann A, Pilarsky C, Bosserhoff AK, Knuechel R. RNA expression profiling of normal and tumor cells following photodynamic therapy with 5-aminolevulinic acid-induced protoporphyrin IX in vitro. Mol Cancer Ther 2005;4:516-28.

17. Ruhdorfer S, Sanovic R, Sander V, Krammer B, Verwanger T. Gene expression profiling of the human carcinoma cell line A-431 after 5 -aminolevulinic acid-based photodynamic treatment. Int J Oncol 2007;30:1253-62.

18. Sanovic R, Krammer B, Grumboeck S, Verwanger T. Time-resolved 
gene expression profiling of human squamous cell carcinoma cells during the apoptosis process induced by photodynamic treatment with hypericin. Int J Oncol 2009;35:921-39.

19. Gollnick SO, Evans SS, Baumann H, Owczarczak B, Maier P, Vaughan L, Wang WC, Unger E, Henderson BW. Role of cytokines in photodynamic therapy-induced local and systemic inflammation. $\mathrm{Br} J$ Cancer 2003;88:1772-9.

20. Seshadri M, Bellnier DA. The vascular disrupting agent 5,6-dimethylxanthenone-4-acetic acid improves the antitumor efficacy and shortens treatment time associated with Photochlor-sensitized photodynamic therapy in vivo. Photochem Photobiol 2009;85:50-6.

21. Yom SS, Busch TM, Friedberg JS, Wileyto EP, Smith D, Glatstein E, Hahn SM. Elevated serum cytokine levels in mesothelioma patients who have undergone pleurectomy or extrapleural pneumonectomy and adjuvant intraoperative photodynamic therapy. Photochem Photobiol 2003;78:75-81.

22. Korbelik M, Sun J, Cecic I. Photodynamic therapy-induced cell surface expression and release of heat shock proteins: relevance for tumor response. Cancer Res 2005;65:1018-26.

23. Kushibiki T, Tajiri T, Tomioka Y, Awazu K. Photodynamic therapy induces interleukin secretion from dendritic cells. Int J Clin Exp Med 2010;3:110-4.

24. Castano AP, Mroz P, Hamblin MR. Photodynamic therapy and antitumour immunity. Nat Rev Cancer 2006;6:535-45.

25. Garg AD, Nowis D, Gołąb J, Agostinis P. Photodynamic therapy: illuminating the road from cell death towards anti-tumour immunity. Apoptosis 2010;15:1050-71.

26. Firczuk M, Nowis D, Gołąb J. PDT-induced inflammatory and host responses. Photochem Photobiol Sci 2011;10:653-63.

27. Cecic I, Korbelik M. Mediators of peripheral blood neutrophilia induced by photodynamic therapy of solid tumors. Cancer Lett 2002;183:43-51.

28. Cecic I, Parkins CS, Korbelik M. Induction of systemic neutrophil response in mice by photodynamic therapy of solid tumors. Photochem Photobiol 2001;74:712-20.

29. Cecic I, Sun J, Korbelik M. Role of complement anaphylatoxin C3a in photodynamic therapy-elicited engagement of host neutrophils and other immune cells. Photochem Photobiol 2006a;82:558-62.

30. Dunkelberger JR, Song WC. Complement and its role in innate and adaptive immune responses. Cell Res 2010;20:34-50.

31. Tegla CA, Cudrici C, Patel S, Trippe R 3rd, Rus V, Niculescu F, Rus H. Membrane attack by complement: the assembly and biology of terminal complement complexes. Immunol Res 2011;51:45-60.

32. Korbelik M, Sun J, Cecic I, Serrano K. Adjuvant treatment for complement activation increases the effectiveness of photodynamic therapy of solid tumors. Photochem Photobiol Sci 2004;3:812-6.

33. Cecic I, Serrano K, Gyongyossy-Issa M, Korbelik M. Characteristics of complement activation in mice bearing Lewis lung carcinomas treated by photodynamic therapy. Cancer Lett 2005;225:215-23.

34. Korbelik M. Complement upregulation in photodynamic therapytreated tumors: Role of Toll-like receptor pathway and NFkappaB. Cancer Lett 2009;281:232-8.

35. van Duijnhoven FH, Aalbers RI, Rovers JP, Terpstra OT, Kuppen PJ. The immunological consequences of photodynamic treatment of cancer, a literature review. Immunobiology 2003; 207:105-13.

36. Cecic I, Stott B, Korbelik M. Acute phase response-associated systemic neutrophil mobilization in mice bearing tumors treated by photodynamic therapy. Int Immunopharmacol 2006b;6:1259-66.

37. Cecic I, Minchinton Al, Korbelik M. The impact of complement activation on tumor oxygenation during photodynamic therapy. Photochem Photobiol 2007;83:1049-55.

38. Cecic I, Korbelik M. Deposition of complement proteins on cells treated by photodynamic therapy in vitro. J Environ Pathol Toxicol Oncol 2006;25:189-203.

39. Stott B, Korbelik M. Activation of complement C3, C5, and C9 genes in tumors treated by photodynamic therapy. Cancer Immunol Immunother 2007;56:649-58.

40. Korbelik M, Cecic I Complement activation cascade and its regulation: relevance for the response of solid tumors to photodynamic therapy. J Photochem Photobiol B 2008;93:53-9.

41. Morgan BP, Marchbank KJ, Longhi MP, Harris CL, Gallimore AM. Complement: central to innate immunity and bridging to adaptive responses, Immunol Lett 2005;97:171-9.
42. Kemper $C$, Atkinson JP. T-cell regulation: with complements from innate immunity, Nat Rev Immunol 2007;7:9-18.

43. Preise D, Oren R, Glinert I, Kalchenko V, Jung S, Scherz A, Salomon Y. Systemic antitumor protection by vascular-targeted photodynamic therapy involves cellular and humoral immunity. Cancer Immunol Immunother 2009;58:71-84.

44. Kabingu E, Vaughan L, Owczarczak B, Ramsey KD, Gollnick SO. CD8+ $T$ cell-mediated control of distant tumours following local photodynamic therapy is independent of CD4+ T cells and dependent on natural killer cells. Br J Cancer 2007;96:1839-48.

45. Thong PS, Ong KW, Goh NS, Kho KW, Manivasager V, Bhuvaneswari R, Olivo M, Soo KC. Photodynamic-therapy-activated immune response against distant untreated tumours in recurrent angiosarcoma. Lancet Oncol 2007;8:950-2.

46. Kabingu E, Oseroff AR, Wilding GE, Gollnick SO. Enhanced systemic immune reactivity to a Basal cell carcinoma associated antigen following photodynamic therapy. Clin Cancer Res 2009;15:4460-6.

47. Elmets CA, Bowen KD. Immunological suppression in mice treated with hematoporphyrin derivative photoradiation. Cancer Res 1986;46:1608-11.

48. Musser DA, Oseroff AR. Characteristics of the immunosuppression induced by cutaneous photodynamic therapy: persistence, antigen specificity and cell type involved. Photochem Photobiol 2001;73:518-24.

49. Gollnick SO, Musser DA, Oseroff AR, Vaughan L, Owczarczak B Henderson BW. IL-10 does not play a role in cutaneous Photofrin photodynamic therapy-induced suppression of the contact hypersensitivity response. Photochem Photobiol 2001b;74:811-6.

50. Hayami J, Okamoto $H$, Sugihara A, Horio T. Immunosuppressive effects of photodynamic therapy by topical aminolevulinic acid. J Dermatol 2007;34:320-7.

51. Yusuf N, Katiyar SK, Elmets CA. The immunosuppressive effects of phthalocyanine photodynamic therapy in mice are mediated by CD4+ and CD8+ T cells and can be adoptively transferred to naive recipients. Photochem Photobiol 2008;84(2):366-70.

52. Matthews YJ, Damian DL. Topical photodynamic therapy is immunosuppressive in humans. Br J Dermatol 2010;162:637-41.

53. Hunt DW, Levy JG. Immunomodulatory aspects of photodynamic therapy. Expert Opin Investig Drugs 1998;7:57-64.

54. Qiang YG, Yow CM, Huang Z. Combination of photodynamic therapy and immunomodulation: current status and future trends. Med Res Rev 2008;28:632-44.

55. Kwitniewski M, Juzeniene A, Glosnicka R, Moan J. Immunotherapy: a way to improve the therapeutic outcome of photodynamic therapy? Photochem Photobiol Sci 2008;7:1011-7.

56. Gołąb J, Wilczyński G, Zagożdżon R, Stokłosa T, Dabrowska A, Rybczyńska J, Wąsik M, Machaj E, Ołdak T, Kozar K, Kamiński R, Giermasz A, Czajka A, Lasek W, Feleszko W, Jakóbisiak M. Potentiation of the anti-tumour effects of Photofrin-based photodynamic therapy by localized treatment with G-CSF. Br J Cancer 2000;82:1485-91.

57. Bellnier DA. Potentiation of photodynamic therapy in mice with recombinant human tumor necrosis factor-alpha. J Photochem Photobiol B 1991;8:203-10.

58. Bellnier DA, Gollnick SO, Camacho SH, Greco WR, Cheney RT Treatment with the tumor necrosis factor-alpha-inducing drug 5,6-dimethylxanthenone-4-acetic acid enhances the antitumor activity of the photodynamic therapy of RIF-1 mouse tumors. Cancer Res 2003;63:7584-90.

59. Seshadri M, Spernyak JA, Mazurchuk R, Camacho SH, Oseroff AR, Cheney RT, Bellnier DA. Tumor vascular response to photodynamic therapy and the antivascular agent 5,6-dimethylxanthenone-4acetic acid: implications for combination therapy. Clin Cancer Res 2005;11:4241-50.

60. Korbelik M, Cooper PD. Potentiation of photodynamic therapy of cancer by complement: the effect of gamma-inulin. $\mathrm{Br} \mathrm{J}$ Cancer 2007;96:67-72.

61. Akramiene D, Aleksandraviciene C, Grazeliene G, Zalinkevicius R Suziedelis K, Didziapetriene J, Simonsen U, Stankevicius E, Kevelaitis E. Potentiating effect of beta-glucans on photodynamic therapy of implanted cancer cells in mice. Tohoku J Exp Med 2010;220:299-306.

62. Separovic D, Bielawski J, Pierce JS, Merchant S, Tarca AL, Bhatti G, Ogretmen B, Korbelik M. Enhanced tumor cures after Foscan photodynamic therapy combined with the ceramide analog LCL29. 
Evidence from mouse squamous cell carcinomas for sphingolipids as biomarkers of treatment response. Int J Oncol 2011;38:521-7.

63. Coupienne I, Bontems S, Dewaele M, Rubio N, Habraken Y, Fulda S, Agostinis P, Piette J. NF-kappaB inhibition improves the sensitivity of human glioblastoma cells to 5 - aminolevulinic acid-based photodynamic therapy. Biochem Pharmacol 2011;81:606-16.

64. Mew D, Wat CK, Towers GH, Levy JG. Photoimmunotherapy: treatment of animal tumors with tumor-specific monoclonal antibodyhematoporphyrin conjugates. J Immunol 1983;130:1473-7.

65. Hasan T. Photosensitizer delivery mediated by macromolecular carrier systems. In: Henderson BW, Dougherty TJ, editor. Photodynamic therapy: basic principles and clinical applications. New York: Marce Dekker, Inc; 1992. p.187-200.

66. Sternberg ED, Dolphin D, Brückner C. Porphyrinbased photosensitizers for use in photodynamic therapy. Tetrahedron 1998;54:4151-202.

67. Yarmush ML, Thorpe WP, Strong L, Rakestraw SL, Toner M, Tompkins RG. Antibody Targeted Photolysis. Crit Rev Ther Drug Carrier Syst 1993;10:197-252

68. Savellano MD, Hasan T. Targeting cells that overexpress the epidermal growth factor receptor with polyethylene glycolated BPD verteporfin photosensitizer immunoconjugates. Photochem Photobiol 2003;77:431-9.

69. Savellano MD, Pogue BW, Hoopes PJ, Vitetta ES, Paulsen KD. Multiepitope HER2 targeting enhances photoimmunotherapy of HER2-overexpressing cancer cells with pyropheophorbide-a immunoconjugates. Cancer Res 2005;65:6371-9.

70. Bhatti M, Yahioglu G, Milgrom LR, Garcia-Maya M, Chester KA, Deonarain MP. Targeted photodynamic therapy with multiply-loaded recombinant antibody fragments. Int J Cancer 2008;122:1155-63.

71. Jalili A, Makowski M, Switaj T, Nowis D, Wilczynski GM, Wilczek E, Chorazy-Massalska M, Radzikowska A, Maslinski W, Biały L, Sienko J, Sieron A, Adamek M, Basak G, Mróz P, Krasnodebski IW, Jakóbisiak M, Gołab J. Effective photoimmunotherapy of murine colon carcinoma induced by the combination of photodynamic therapy and dendritic cells. Clin Cancer Res 2004;10:4498-508.

72. Saji H, Song W, Furumoto K, Kato H, Engleman EG. Systemic antitumor effect of intratumoral injection of dendritic cells in combination with local photodynamic therapy. Clin Cancer Res 2006;12:2568-74.

73. del Carmen MG, Rizvi I, Chang Y, Moor AC, Oliva E, Sherwood M, Pogue B, Hasan T. Synergism of epidermal growth factor receptortargeted immunotherapy with photodynamic treatment of ovarian cancer in vivo. Natl Cancer Inst 2005;97:1516-24.

74. Jiang F, Zhang X, Kalkanis SN, Zhang Z, Yang H, Katakowski M, Hong X, Zheng X, Zhu Z, Chopp M. Combination therapy with antiangiogenic treatment and photodynamic therapy for the nude mouse bearing U87 glioblastoma. Photochem Photobiol 2008;84:128-37.

75. Bhuvaneswari R, Thong PS, Gan YY, Soo KC, Olivo M. Evaluation of hypericin-mediated photodynamic therapy in combination with angiogenesis inhibitor bevacizumab using in vivo fluorescence confocal endomicroscopy. J Biomed Opt 2010;15:011114.

76. Korbelik, M., Sun, J. Photodynamic therapy-generated vaccine for cancer therapy. Cancer Immunol Immunother 2006;55:900-9.

77. Korbelik M. Photodynamic therapy-generated cancer vaccines. Methods Mol Biol 2010;635:147-53.

78. Korbelik M, Stott B, Sun J. Photodynamic therapy-generated vaccines: relevance of tumour cell death expression. Br J Cancer 2007;97:1381-7.

79. Zhang H, Ma W, Li Y. Generation of effective vaccines against liver cancer by using photodynamic therapy. Lasers Med Sci 2009;24:54952.

80. Shixiang Y, Xi S, Junliang L, Shanyi Z, Xingke X, Meiguang Z, Kai W, Fangcheng $L$. Antitumor efficacy of a photodynamic therapy-generated dendritic cell glioma vaccine. Med Oncol 2010 [Epub ahead of print] doi:10.1007/s12032-010-9713-y 